\title{
Interações comunicativas entre uma professora e um aluno com autismo na escola comum: uma proposta de intervenção'
}

Rosana Carvalho Gomes"

Débora R. P. Nunes"

\section{Resumo}

Os aspectos polêmicos que envolvem o processo de inclusão de educandos com autismo nas salas de aula comuns têm suscitado debates amplos nas últimas décadas. Um dos principais desafios apontados por professores para realizar esse tipo de inclusão são os prejuízos na comunicação, tipicamente evidenciados por alunos com esse diagnóstico. Desse modo, torna-se imperativo o desenvolvimento de programas de intervenção focados no desenvolvimento das habilidades comunicativas desses alunos. Tendo isso em vista, o objetivo do presente estudo foi avaliar os efeitos de um programa de intervenção nas interações comunicativas, no contexto da sala de aula comum, entre um aluno não falante de 10 anos, com diagnóstico de autismo, e sua professora. Os dados foram coletados em uma escola de Ensino Fundamental, localizada na cidade de Natal (RN). No programa de intervenção, a professora foi capacitada a empregar estratégias do ensino naturalístico e recursos da comunicação alternativa ampliada para aumentar a frequência de interações com o aluno durante três rotinas da sala de aula. Com base em um delineamento de pesquisa quase experimental do tipo A-B (linha de base e tratamento) foram identificadas mudanças qualitativas e quantitativas nas interações professoraaluno, logo após a implementação do programa de intervenção. Limitações do estudo são apresentadas e discutidas a partir dos dados observacionais e registros das interações entre a díade.

\section{Palavras-chave}

Educação inclusiva - Autismo - Comunicação alternativa e ampliada.

I- Dissertação de Mestrado financiada pela CAPES.

II- Universidade Federal do Rio Grande do Norte, Natal, RN, Brasil.

Contatos: deboranunes@ufrnet.br;

rosanagomescarvalho@hotmail.com 


\title{
Communicative interactions between a teacher and a student with autism in regular schools: an intervention proposal'
}

\author{
Rosana Carvalho Gomes" \\ Débora R. P. Nunes"
}

\begin{abstract}
The controversial aspects involving the process of inclusion of students with autism in public school classrooms have sparked extensive debate in recent decades. One of the main challenges faced by teachers to perform this type of inclusion are impairments in communication, typically evidenced by students with this diagnosis. Thus, it becomes imperative to develop intervention programs focused on the development of the communicative skills of these students. Keeping this in view, the aim of this study was to evaluate the effects of a program of intervention on the communicative interactions, in the context of common classrooms, between a non-speaking student aged 10 years, diagnosed with autism, and his teacher. Data were collected in a primary education school located in Natal city, Rio Grande do Norte state. In the intervention program, the teacher was trained to employ naturalistic teaching strategies and resources of extended alternative communication to increase the frequency of interactions with the student during three routines of the classroom. Based on a quasi-experimental research design of $A B$ type (baseline and treatment), we identified qualitative and quantitative changes in teacher-student interactions shortly after the implementation of the intervention program. Limitations of the study are presented and discussed on the basis of observational data and records of the interactions between the dyad.
\end{abstract}

\section{Keywords}

Inclusive education - Autism - Extended and alternative communication. 


\section{Introdução}

0 autismo é um transtorno do desenvolvimento neurobiológico, definido por critérios essencialmente clínicos. Passível de ser detectado antes dos 36 meses de vida, o autismo é o mais prevalente e conhecido dentre os Transtornos Globais do Desenvolvimento (TGD), acometendo homens em proporção quatro vezes superior às mulheres. Para que se tenha uma dimensão do contingente populacional de que estamos tratando, ressaltamos que pesquisas epidemiológicas internacionais indicam que os TGD afetam um em cada 160 indivíduos (ELSABBAGH, 2012). No Brasil, os valores são ainda maiores: um estudo conduzido por Paula et al. (2011) sugere que o autismo e suas variações afetam um em cada 350 brasileiros.

No que se segue, passamos a descrever algumas das características típicas de pessoas diagnosticadas com autismo, consideradas por nós como relevantes para o presente estudo. Quanto ao comportamento, à interação social e à comunicação de pessoas diagnosticadas como autistas, percebem-se prejuízos qualitativos e quantitativos bastante marcados (APA, 2002). Nos casos de comportamentos atípicos, por exemplo, pode haver adesão aparentemente inflexível a rotinas desadaptativas, rituais não funcionais, padrões restritos de interesses, além de maneirismos motores estereotipados e repetitivos.

Os prejuízos qualitativos nas interações sociais são evidentes nos comportamentos não verbais, tais como dificuldades em manter o contato visual ou a presença de expressões faciais e posturas corporais atípicas durante interação interpessoal. Cabe, ainda, ressaltar aspectos como o fracasso em desenvolver relacionamento com pares, a falta de reciprocidade emocional e a ausência de tentativas em compartilhar prazer, interesses ou realizações com o outro (APA, 2002).

As alterações da linguagem podem variar de acordo com o grau de severidade do quadro clínico. Para que se tenha uma ideia, aproximadamente 30\% dos autistas são desprovidos da linguagem verbal (KLIN, 2006). Outros, apesar de desenvolverem a linguagem, não apresentam intenção comunicativa ou exibem atipicidades, como ecolalia, inversão pronominal e dificuldades na prosódia (MACEDO; ORSATI, 2011). Adicionalmente, o sistema de comunicação gestual, tanto em indivíduos vocais quanto não vocais, pode ser deficitário (APA, 2002). Além disso, o cometimento na compreensão da linguagem falada é outra característica comum dessa população (MACEDO; ORSATI, 2011; HALL, 2012).

A tríade sintomatológica que caracteriza o perfil da pessoa com autismo não pode ser ignorada no contexto da escola. As especificidades da síndrome podem interferir no aprendizado e na inclusão social desses indivíduos em ambientes educacionais (HALL, 2012; NUNES, 2012). A proximidade física com os colegas, a dificuldade em apreender regras sociais, a falta de compreensão de instruções verbais ou a incapacidade em utilizar a linguagem falada podem representar desafios para essa população.

Vale ressaltar, ainda, que estudos nacionais e internacionais revelam que os professores se sentem despreparados para lidar com a sintomatologia autista no contexto da sala de aula comum, conforme já estudado em diversas ocasiões (MCGREGOR; CAMPBELL, 2001; ROBERTSON; CHAMBERLAIN; KASARI, 2003; ALVES, 2005; MARTINS, 2007; SERRA, 2008). Ao serem interrogados, esses docentes indicam que um dos principais desafios é educar alunos que apresentam limitada competência comunicativa (MCGREGOR; CAMPBELL, 2001).

Os prejuízos comunicativos tipicamente observados nessa população podem ser minimizados pelo uso da Comunicação Alternativa e Ampliada (CAA) (NUNES, 2008; WENDT, 2009; MACED0; ORSATI, 2011). A comunicação alternativa é aquela em que os recursos substituem a fala, e a ampliada é aquela em que esses recursos suplementam a fala.

Estudos sobre CAA no Brasil têm crescido nas últimas décadas (CUNHA, 1997; ARAUJO; 
NUNES, 2003; DELIBERATO, 2009; SCHIRMER; NUNES et al., 2009; PAULA; ENUMO, 2007; WALTER; ALMEIDA, 2010). Trata-se de uma área da prática clínica e educacional que objetiva compensar, temporária ou permanentemente, os prejuízos na comunicação expressiva e receptiva. Ela envolve o uso de gestos manuais, expressões faciais e corporais, símbolos gráficos (fotografias, gravuras, desenhos, linguagem alfabética, objetos reais e miniaturas), voz digitalizada ou sintetizada, dentre outros meios que podem ser usados para efetuar a comunicação face a face de pessoas que apresentam limitações no uso e/ou na compreensão da linguagem oral.

A metodologia de intervenção utilizada para capacitar populações com prejuízos na linguagem a utilizar os recursos da CAA é o Ensino Naturalístico (EN), o qual se tem destacado em muitas das pesquisas realizadas na área (LAMONICA, 1993; NUNES, 2000; PAULA; NUNES, 2003; ARAUJO; NUNES, 2003; NUNES et al., 2009). O EN é um modelo geral de intervenção em linguagem, que inclui diversos programas de tratamento (CUNHA, 1997). De acordo com Nunes (1992), os seguintes elementos são considerados comuns a esses programas: a) o uso de reforçadores indicados pelo aprendiz; b) o interesse da criança, considerado como fio condutor no processo de aprendizagem; c) as contingências do meio natural utilizadas para o aumento na frequência de emissões de respostas desejadas; d) a ênfase dada à competência comunicativa do educando em vez da linguagem per se; e e) o ensino realizado durante atividades cotidianas em contextos e ambientes naturais.

Dentre as estratégias de ensino derivadas da abordagem naturalística, destacam-se: o arranjo ambiental, o modelo dirigido à criança, o mando e a espera. Esses procedimentos, que serão posteriormente defınidos no presente artigo, permitem à criança aumentar a frequência de interação com pessoas e objetos do seu meio (CUNHA, 1997).
Com relação à eficácia desse tipo de abordagem, ressaltamos que, em uma avaliação de programas de intervenção dirigidos para populações com autismo, o uso das Estratégias Naturalísticas de Ensino (ENE) foi categorizado como uma prática cientificamente válida ${ }^{1}$ (NATIONAL AUTISM CENTER, 2013). No contexto educacional, no entanto, o número de estudos que avaliam a eficácia das ENE no ensino da CAA para populações com autismo é limitado (NUNES et al., 2009).

A pesquisa realizada por Nunes et al. (2009) investigou o trabalho de uma professora que recebeu capacitação para utilizar as ENE para ensinar uma menina autista, de 6 anos, a usar os recursos da CAA em um ambiente de sala de aula especial. Os resultados do estudo evidenciaram que a professora, após o programa de treinamento, passou a se comunicar em vários contextos de interação com a criança. Houve generalizações das práticas aprendidas para outro contexto e aumento na frequência de turnos comunicativos da criança.

Tendo em vista a relevância desse tipo de investigação, o presente artigo tem como propósito a ampliação dos estudos nesse campo, focando o uso dos recursos da CAA por aluno com autismo, no contexto da escola comum. Assim, visamos a avaliar os efeitos do emprego de um programa de capacitação do professor para a utilização dos recursos da CAA com um aluno com autismo, por meio de ENE.

\section{Metodologia da pesquisa}

0 presente estudo foi conduzido com Luan, um aluno com diagnóstico de autismo, e Sônia, sua professora. Na ocasião em que realizamos a pesquisa, o menino havia completado 10 anos e estava matriculado no $3^{\circ}$ ano de uma escola comum do Ensino Fundamental. Aos 3 anos, recebera diagnóstico de autismo, por um neuropediatra. Adicionalmente, por meio do

1- Práticas cientificamente válidas são descritas como métodos e técnicas que tenham produzido resultados positivos quando testados experimentalmente (SIMPSON, 2005). 
instrumento Childhood Autism Rating Scale CARS $^{2}$ (PEREIRA et al., 2008), aplicado pelas autoras no início da pesquisa, obtiveram como resultado a constatação de que o grau de autismo de Luan foi considerado severo (52 pontos).

No que se refere ao comportamento, suas verbalizações eram limitadas e desprovidas de intenção comunicativa. A ausência de fala funcional não era compensada pelo uso de gestos ou outras formas não verbais de comunicação. 0 aluno demonstrava, ainda, dificuldade em interagir com seus pares, limitada compreensão da fala e exibição de estereotipias motoras e inflexibilidade comportamental.

Sônia, 41 anos, trabalhava há 14 como professora. Sua formação profissional era de nível médio, no curso de magistério. Embora tivesse experiência como docente em outros estabelecimentos de ensino, não havia trabalhado com crianças com necessidades educacionais especiais, até o momento da pesquisa.

0 estudo foi conduzido em uma sala de aula comum de $3^{\circ}$ ano de uma escola da rede privada de ensino. A instituição, localizada em um bairro de classe média da cidade de Natal (RN), atendia aproximadamente a 120 alunos da Educação Infantil ao Ensino Fundamental.

Foram utilizados alimentos, jogos, atividades pedagógicas e pictogramas contendo fotografias ou símbolos $\mathrm{PCS}^{3}$ dos objetos ou atividades realizadas durante as rotinas escolares. Uma câmera filmadora portátil, uma câmera fotográfica digital e um laptop foram os equipamentos usados.

Para registrar as interações entre professora e aluno, optou-se pelo uso de dois roteiros de entrevista individual e um diário de campo, no qual foram registradas as impressões e anotações da pesquisadora (1 1 autora).

2- CARS - entrevista estruturada, traduzida e validada no Brasil por Pereira e colaboradores (2008), que avalia o comportamento em 14 habilidades tipicamente afetadas pelo autismo. A pontuação varia de 15 a 60, sendo 30 o ponto de corte para o autismo (PEREIRA et al., 2008). A escala auxilia no diagnóstico diferencial e na classificação do grau de severidade da síndrome, como leve, moderada ou severa. A aplicação pode ser feita por profissionais de qualquer área com experiência em autismo. 3- Símbolo PCS - Picture Communication Symbols.
0 presente estudo caracteriza-se como uma pesquisa quase experimental, com um delineamento do tipo A-B (KENNEDY, 2005). As respostas comunicativas da díade professoraaluno constituíram as variáveis investigadas. Essas variáveis foram, inicialmente, categorizadas em tipos de turno, conforme indicado no Quadro 1 abaixo:

Quadro 1 - Tipos de turnos

\begin{tabular}{c:c} 
Turno & \multicolumn{1}{c}{ Definição } \\
\hline \multirow{3}{*}{ Resposta } & $\begin{array}{c}\text { Enunciados verbais/vocais, gestuais (gestos, língua de } \\
\text { sinais e expressões faciais) ou pictográficos emitidos } \\
\text { pelo aluno/professora após pergunta/solicitação do } \\
\text { parceiro. }\end{array}$ \\
\hline \multirow{2}{*}{ Iniciativa } & Enunciados verbais/vocais, gestuais (gestos, língua de \\
& sinais e expressões faciais) ou pictográficos emitidos \\
& pelo aluno/professora sem ocorrência de solicitação \\
de resposta do parceiro.
\end{tabular}

Fonte: Elaboração das autoras do artigo.

Os turnos (iniciativa e resposta) foram, posteriormente, categorizados em cinco modalidades, conforme indicado no Quadro 2, abaixo:

Quadro 2 - Modalidade de turnos

\begin{tabular}{|c|c|}
\hline Modalidade & Definição \\
\hline Gestual & $\begin{array}{l}\text { Olhar, expressão facial, contato corporal e ação } \\
\text { gestual (convencional; simbólica e de contenção) } \\
\text { emitidos pelo aluno ou professora durante um } \\
\text { turno (iniciativa ou resposta). }\end{array}$ \\
\hline Verbal/vocal & $\begin{array}{l}\text { Verbalizações, sons guturais, gemidos, } \\
\text { murmúrios, balbucios ou vocábulos não } \\
\text { inteligíveis emitidos pelo aluno ou professora } \\
\text { durante um turno (iniciativa ou resposta). }\end{array}$ \\
\hline Pictográfica & $\begin{array}{l}\text { Uso de pictograma (fichas com fotos da rotina e } \\
\text { objetos do aluno dispostas na mesa, ou em uma } \\
\text { pasta de comunicação) pelo aluno ou professora } \\
\text { durante um turno (iniciativa ou resposta). }\end{array}$ \\
\hline $\begin{array}{c}\text { Gestual e } \\
\text { pictográfico }\end{array}$ & $\begin{array}{l}\text { Uso simultâneo de duas modalidades: gráfico } \\
\text { (pictogramas) e gestual (gestos manuais/ } \\
\text { corporais e expressões faciais) pelo aluno ou } \\
\text { professora durante um turno (iniciativa ou } \\
\text { resposta). }\end{array}$ \\
\hline $\begin{array}{l}\text { Verbal/vocal e } \\
\text { pictográfico }\end{array}$ & $\begin{array}{l}\text { Uso simultâneo de duas modalidades: verbal } \\
\text { (fala inteligível)/vocal (vocábulos não inteligíveis) } \\
\text { e gráfico (pictogramas) pelo aluno ou professora } \\
\text { durante um turno (iniciativa ou resposta). }\end{array}$ \\
\hline
\end{tabular}

Fonte: Elaboração das autoras do artigo. 
Como se trata de um estudo no qual as autoras participaram ativamente das interações entre Luan e Sônia, cabe apontar para o fato de que a primeira autora, com formação em pedagogia, atuou como agente de capacitação. Ela exercia, há dez anos, a função de pedagoga, tendo trabalhado durante cinco anos com crianças com deficiência em escola comum no estado do Piauí. No presente manuscrito, essa será identificada como pesquisadora.

0 projeto foi inicialmente submetido ao Comitê de Ética em Pesquisa da Universidade Federal do Rio Grande do Norte (Parecer $\mathrm{n}^{-}$ 038/2010; CAAE no 0212.0 051.000-09). A formalização do consentimento se deu por meio de um Termo de Consentimento Livre e Esclarecido (TCLE), assinado pela mãe do aluno e pela professora.

Após a aprovação do projeto pelo Comitê de Ética e a assinatura do TCLE, o estudo foi operacionalizado em seis etapas distintas: entrevistas/observações, treinamento dos assistentes de pesquisa, identificação das rotinas-alvo, linha de base, capacitação e intervenção. Cada uma delas foi descrita abaixo:

\section{Etapa 1: entrevistas/observações.}

A pesquisadora realizou uma entrevista com a mãe e outra com a professora de Luan, na casa e na escola do aluno, respectivamente. Os encontros, com duração aproximada de 60 minutos, foram estruturados considerandose um roteiro de entrevista previamente elaborado pelas autoras. Com o propósito de complementar os dados das entrevistas, assim como identificar as habilidades comunicativas do aluno no contexto escolar, a pesquisadora realizou quatro sessões de observação de Luan, com duração média de 60 minutos, no ambiente escolar. Os dados foram devidamente registrados em um diário de campo.

\section{Etapa 2: treinamento dos assistentes} de pesquisa.

Duas alunas graduandas do curso de pedagogia da Universidade Federal do Rio Grande do Norte foram treinadas no sentido de categorizarem as variáveis previamente definidas. Ambas foram bolsistas, durante três anos, em um projeto de pesquisa envolvendo o uso da comunicação alternativa para alunos com autismo. A capacitação dessas duas bolsistas foi implementada pelas autoras e envolveu procedimentos como discussões, análise de vídeos e leituras. Após a familiarização com os procedimentos empregados, as assistentes classificaram as sessões de linha de base e intervenção. Ao término das videogravações, realizadas pela pesquisadora, as sessões eram então entregues às alunas. Cada assistente ficou responsável pela categorização de 50\% das sessões. Com o propósito de verificar o grau de fidedignidade das categorias de respostas analisadas no presente estudo, a pesquisadora, atuando como segunda avaliadora, randomicamente avaliou 50\% do total das sessões analisadas pelas duas assistentes. Vale ressaltar que as assistentes de pesquisa atuaram como primeiras avaliadoras. 0 cálculo de concordância foi obtido por meio do índice de concordância descrito por Fagundes (1985). Esse índice variou entre 73 e 100\%, indicando boa fidedignidade.

\section{Etapa 3: Identificação das rotinas alvo.}

A partir dos registros de observações e entrevistas foram selecionadas, junto com a professora, três rotinas durante as quais ocorreriam as intervenções: no decorrer do lanche, em atividades pedagógicas e na entrada da escola. Essas rotinas foram escolhidas porque aconteciam diariamente e pelo fato de a professora expressar dificuldade em se comunicar com o aluno durante as referidas atividades. No presente artigo, serão 
apresentados os resultados das duas primeiras rotinas: lanche e atividade pedagógica.

\section{Etapa 4: Linha de base.}

Nessa fase, a professora foi instruída a interagir livremente com o aluno nas três rotinas selecionadas. As sessões foram videografadas, e a frequência de turnos e a modalidade de respostas utilizadas pela díade foram mensuradas. Houve também avaliação a respeito do fato de a professora utilizar ou não, de forma espontânea, as ENE. Os critérios foram definidos no Quadro 3, abaixo: ${ }^{4}$

Quadro 3 - Estratégias naturalísticas de ensino utilizadas no estudo

\begin{tabular}{c|c}
\hline Estratégias & \multicolumn{1}{c}{ Definição } \\
\hline \multirow{3}{*}{ Arranjo ambiental } & Consiste na organização do ambiente com \\
& pictogramas acessíveis ao aluno e objetos de \\
& seu interesse dispostos em seu campo visual, \\
& mas fora de seu alcance. \\
& A professora tece comentários, formula \\
& perguntas e faz solicitações utilizando, \\
& simultaneamente, a linguagem oral e o sistema \\
& pictográfico de comunicação. \\
\hline \multirow{3}{*}{ Mando com CAA } & A professora oferece ajuda física com o \\
& objetivo de guiar o aluno para fixar a atenção \\
& no que está fazendo. Esse procedimento é \\
& acompanhado por comentários, perguntas ou \\
& solicitações verbais. \\
\hline \multirow{3}{*}{ Espera } & A professora aguarda, de forma silenciosa, a \\
& iniciativa de interação do aluno. \\
\hline
\end{tabular}

Fonte: Elaboração das autoras do artigo.

A análise dessas estratégias foi realizada da seguinte maneira: a pesquisadora assistia às sessões videografadas, as quais haviam sido codificadas, e transcrevia os episódios em que as ENE eram utilizadas por Sônia.

\section{Etapa 5: capacitação}

Essa etapa teve início quando foi evidenciada, por meio de inspeção visual

4- Essas estratégias foram adaptadas de estudos realizados previamente por Oliveira (2002), Souza (2000), Nunes (2000; 2005) e Danelon (2009). dos gráficos, a estabilidade na frequência de turnos da professora na rotina do lanche. Foram realizados, na escola, três encontros de capacitação com a professora. Nesses episódios, Sônia compartilhou com a pesquisadora seu planejamento bimestral, no qual estavam descritos os conteúdos acadêmicos. Em seguida, foram apresentados segmentos de sessões de linha de base à professora. A partir do material videografado, a professora e a pesquisadora elencaram fatores que pareciam prejudicar a interação da díade, assim como aspectos positivos do comportamento de Luan e da própria docente. A partir dessas discussões, foram descritos os conceitos de Comunicação Alternativa e Ampliada e apresentadas as quatro ENE, previamente definidas neste manuscrito. Com o auxílio da pesquisadora, foram confeccionados pictogramas ${ }^{5}$ a serem empregados durante as três rotinas e reelaboradas as atividades acadêmicas apresentadas no planejamento de Sônia.

\section{Etapa 6: intervenção}

Ao término da capacitação, Sônia foi instruída a utilizar as estratégias aprendidas nas rotinas em que recebeu o treinamento. Ela não recebia instruções da pesquisadora durante esses episódios, mas, nos encontros subsequentes, a pesquisadora fornecia dicas pontuais sobre as interações previamente realizadas. As rotinas foram videografadas, e, posteriormente, analisados: a frequência de turnos, a modalidade de respostas da díade e os tipos de ENE empregados pela professora.

Dois roteiros de entrevista foram elaborados pelas autoras. No instrumento utilizado com a mãe constavam itens sobre o desenvolvimento do aluno, seu histórico social e escolar, assim como suas rotinas em casa. Com a professora, o roteiro incluía perguntas sobre o comportamento de Luan em sala de aula e os tipos de atividades realizadas com o aluno. As entrevistas foram gravadas e transcritas pela pesquisadora.

5- Fotos da rotina de Luan na sala de aula (lavar as mãos, lancheira, biscoito, batata, água). 
As sessões de linha de base e intervenção foram videografadas pela pesquisadora. 0 tempo de duração das interações variava de cinco a dez minutos, aproximadamente. Para fins de análise e controle da variável tempo, apenas os primeiros cinco minutos de interação foram considerados nas avaliações.

A análise dos dados ocorreu em duas etapas. Inicialmente, as variáveis turno e modalidade de respostas foram codificadas pelas assistentes de pesquisa e pela pesquisadora. A frequência dessas variáveis foi disposta em gráficos. Posteriormente, a pesquisadora revisou as sessões codificadas e transcreveu os episódios em que as ENE foram empregadas pela professora.

Tratando-se de uma pesquisa quase experimental (A-B), a análise ocorreu por meio de inspeção visual dos dados plotados graficamente. Dessa forma, as variáveis (turno e modalidade de respostas) foram categorizadas e, posteriormente, suas frequências disponibilizadas em gráficos.

0 critério para finalizar a fase de linha de base e iniciar a capacitação foi a estabilidade observada na frequência de turnos da professora em uma das rotinas selecionadas, conforme exposto anteriormente. Em seguida, as mesmas sessões foram analisadas pela pesquisadora, que transcreveu os episódios em que as ENE foram empregadas nas fases de linha de base e de intervenção. As informações dos gráficos e as transcrições da pesquisadora foram complementadas com os dados das entrevistas e do diário de campo.

\section{Resultados}

0 objetivo geral do presente estudo foi avaliar os efeitos de um programa de intervenção nas interações comunicativas entre um aluno com diagnóstico de autismo e sua professora, no contexto da sala de aula comum. A partir desse objetivo, três questões norteadoras da pesquisa foram elaboradas:

1. Quais os efeitos do programa de capacitação no uso de estratégias de ensino empregadas pela professora?
2. Quais os efeitos do programa de capacitação nos turnos (iniciativas e respostas) da professora e do aluno?

3. Quais os efeitos do programa de capacitação nas modalidades dos turnos da díade?

As respostas foram extraídas dos diários de campo e da análise das sessões videografadas, no decorrer dos cinco meses de estudo. No total, foram realizadas 22 sessões (11 de linha de base e 11 de intervenção), em cada rotina.

Quanto aos efeitos do programa de capacitação no uso das estratégias de ensino empregadas pela professora, destacou-se o fato de que antes da intervenção foram detectadas situações nas quais as ENE poderiam ter sido empregadas no momento do lanche, o que não ocorreu. Esse fato foi particularmente evidenciado na sessão três, linha de base, descrita a seguir:

Neste dia há dois cartões sobre a mesa de Luan, o da água e o da atividade pedagógica. Outros cartões de alimentos (batata e biscoito) e atividades rotineiras (lavar as mãos) estão na mesa da professora, fora do campo visual do aluno. A professora se aproxima de Luan e diz: “Lanchar, vambora!" Ela o conduz pela mão até o banheiro e fornece ajuda física para que ele lave as mãos. Eles voltam para a sala de aula. Luan senta em sua carteira e a professora caminha até a prateleira. Ela pega a lancheira de Luan, abre e leva até ele. Ele olha para a lancheira. Ela pergunta: "Você quer batatinha ou biscoito?". Ele pega o pacote de batatas. Ela toma o pacote das mãos de Luan, abre e devolve a ele. (GOMES, cd 1, 2010)

Na sessão explicitada acima, alguns dos pictogramas que Luan poderia ter utilizado durante a interação estavam fora de seu campo visual. 0 emprego de estratégias como o mando com CAA, a espera e o arranjo ambiental pela professora seria apropriado no contexto descrito. Sendo assim, ela poderia ter 
sinalizado a rotina de lavar as mãos e lanchar utilizando os pictogramas que estavam em sua mesa (mando com CAA). Da mesma forma, poderia ter mostrado ao aluno os pictogramas da batata e do biscoito, incitando-o a indicar o que gostaria de lanchar. Em seguida, em vez de abrir o pacote de batatas para ele, poderia ter utilizado o procedimento de espera para estimular a iniciativa de interação do aluno. 0 saco de batatas poderia ter permanecido com a professora e oferecidas poucas batatas, por vez, a ele. Isso caracterizaria o procedimento de arranjo ambiental, que poderia favorecer o aumento na frequência de iniciativas de interação do aluno.

0 relato da sessão cinco (linha de base) evidencia a carência de uso das ENE durante as rotinas pedagógicas. Nessa sessão, a turma está realizando uma atividade de matemática enquanto Luan senta no fundo da sala manipulando, de forma estereotipada, um pincel. Na mesa de Luan há seis pictogramas, duas cédulas de 2 e 5 reais e duas cópias pequenas das mesmas notas. A proposta da atividade é para que Luan coloque as cópias das cédulas sobre as notas originais.

A professora se aproxima de Luan e retira o pincel de sua mão, dizendo: "Tá bom, você já brincou demais!”. Ela puxa o menino para cima, pelas mãos. Ele resiste, contraindo o corpo para o chão. Ela diz: "Venha!". Ele levanta e senta na carteira. Ela mostra: "Olha Luan, 2 reais! Coloca aqui, ó!”. Ela aponta para a nota original, solicitando que ele coloque a cópia sobre ela. (GOMES, cd 1, 2010)

A falta de responsividade de Luan pode ter sido em função da dificuldade de compreender a fala da professora. Assim, a professora poderia ter utilizado os pictogramas das atividades enquanto dava comandos verbais ao aluno (mando com CAA). Cabe enfatizar que o uso de duas modalidades de expressão (verbal e pictográfica) pode favorecer a compreensão de alguns alunos com diagnóstico de autismo (HEFLIN; ALAIMO, 2007).

Apesar de ter acesso aos pictogramas na interação descrita, Luan não os utilizou como alternativa de expressão. Podemos atribuir esse comportamento à falta de instruções explícitas de como utilizá-los. Isso porque estudos anteriores apontam que a mera exposição da pessoa com autismo aos recursos da CAA pode ser pouco eficaz para o desenvolvimento de novas formas de expressão (NUNES et al., 2009).

Após o programa de capacitação, foram identificados episódios em que as estratégias de ensino foram adequadamente utilizadas. 0 relato da sessão 16 (intervenção) abaixo, indicou o uso apropriado do arranjo ambiental durante a atividade de lanche:

Luan está sentado no chão no canto da sala. Na carteira dele, localizada ao lado da professora, há oito cartões de CAA, incluindo o pictograma da lancheira e do copo. A lancheira e o copo encontram-se na prateleira, no canto da sala, à vista dele, mas fora de seu alcance. (GOMES, cd 2, 2010)

No exemplo acima, observa-se o uso de arranjo ambiental, uma vez que a professora colocou os objetos à vista do aluno, mas longe de seu alcance. Essa organização do ambiente físico pode instigar, conforme evidenciado na literatura, iniciativas de interação social (NUNES, 1992). No caso de Luan, poderia estimulá-lo a utilizar os pictogramas para solicitar sua lancheira, que estava inacessível.

$\mathrm{Na}$ atividade pedagógica da sessão 16, descrita a seguir, o aluno tinha à sua frente várias gravuras de animais separados por quantidade e colocados em sequência de ordem numérica. A proposta da atividade era que Luan colocasse duas fichas ao lado de cada gravura.

A professora aponta para a gravura e diz: "Olhe uma vaquinha Luan! Coloca aqui Luan, o número 1 de uma vaquinha!". Ela permanece em silêncio, observando o 
menino por alguns segundos. Ele pega a figura da vaca. Ela verbaliza: "A vaquinha não Luan, o numeral 1. Vá Luan, uma vaquinha, o número 1!". Luan posiciona a mão sobre o numeral 1 e olha para a professora. Ela aponta para a gravura da vaca e, em seguida, para o numeral. Ela diz: "Agora uma bolinha, pega Luan!". Ele pega a ficha com as bolinhas e põe ao lado da figura da vaca. Ela verbaliza e aponta para as fichas: "Olha Luan, que lindo! Uma vaquinha, o numeral 1 e uma bolinha! Muito bem Luan! [...]”. (GOMES, 2010, cd 2)

No episódio acima descrito, a professora realizou a tarefa com Luan utilizando as gravuras da atividade e a linguagem verbal, de forma simultânea. Sempre que o aluno desviava o olhar ou resistia em pegar os materiais, ela chamava a sua atenção, pegava sua mão e colocava em cima da gravura, reiniciando a ação com comando de voz e indicação das fichas. 0 pareamento de estímulos verbais e visuais empregado por Sônia pode ter favorecido a compreensão do aluno, mantendo-o atento à tarefa.

0 procedimento de espera ocorreu quando a professora pediu para Luan pegar as gravuras e colocar nos lugares apontados por ela. Nesses episódios, era dado um tempo de aproximadamente dez segundos para ele dar a resposta. Quando não havia resposta, a professora repetia a ação, provendo dicas verbais ou ajudando-o fisicamente no prosseguimento da atividade.

Apresentados alguns dos principais procedimentos verificados na interação entre Luan e Sônia, no que se segue apresentam-se os efeitos do programa de capacitação nos turnos da díade nas rotinas investigadas, por meio do gráfico 1, a qual indica a frequência de turnos da díade nas sessões de lanche.

\section{Gráfico 1 - Lanche: frequência de turnos da professora e do aluno}

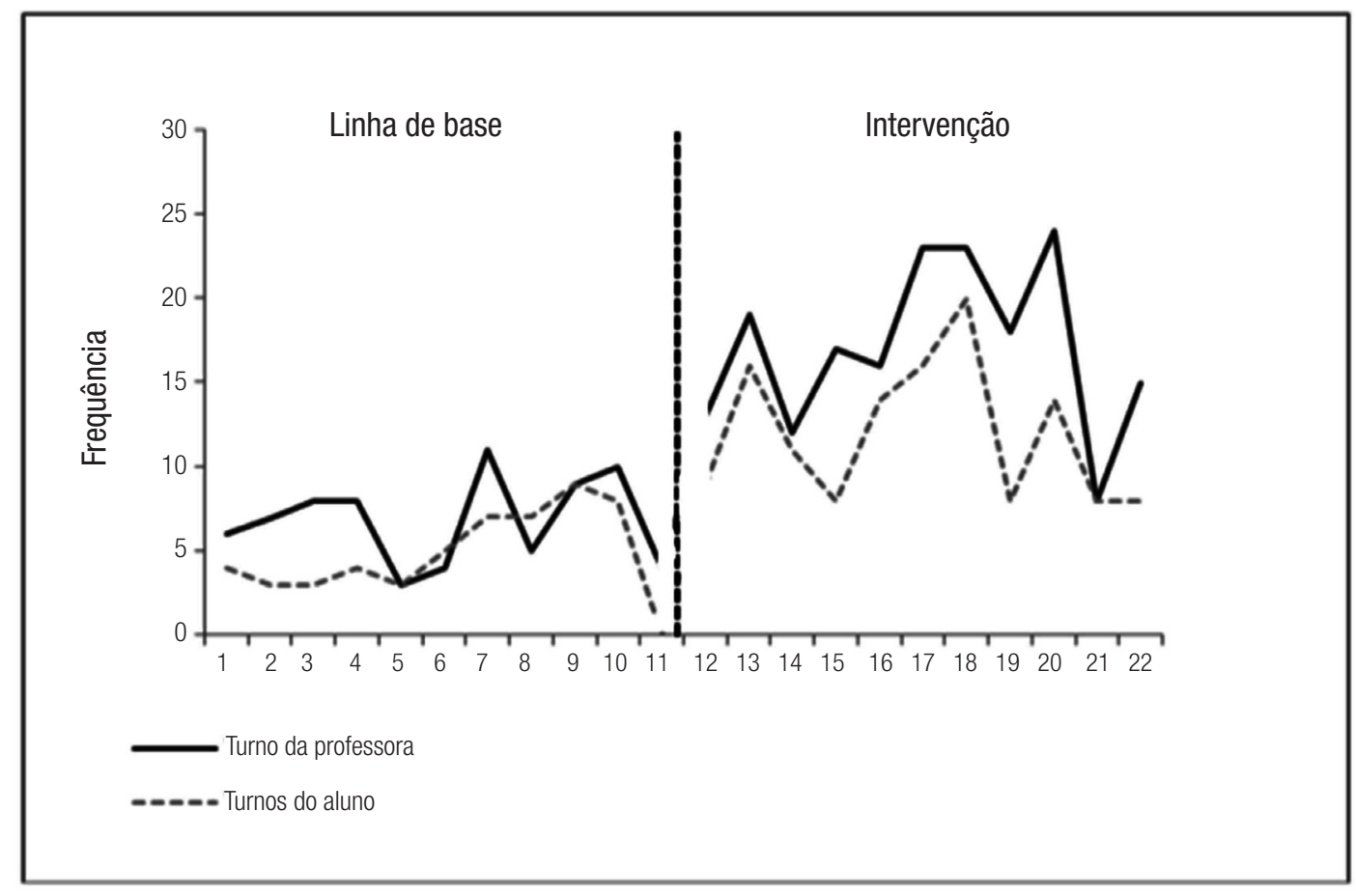

Fonte: dados da pesquisa. 
0 Gráfico 1 sugere relativa estabilidade e baixa frequência de turnos comunicativos da professora e do aluno nas sessões de linha de base. Esse fenômeno pode ser justificado pelo distanciamento físico da díade professora-aluno. No momento do lanche, Sônia tipicamente entregava os alimentos a Luan e retornava à sua mesa. Ele, por sua vez, permanecia em seu assento, até consumir a merenda. A interação de Sônia com Luan limitava-se a comandos verbais, solicitando sua permanência na carteira até finalizar o lanche. Ele, por vezes, vocalizava e dirigia o olhar para a professora, mas, em geral, suas iniciativas de interação não eram percebidas por ela.

0 aumento na frequência de ocorrência de turnos da díade na fase intervenção pode ser observado no gráfico 1. Essa tendência ascendente pode ter sido ocasionada pelas estratégias implementadas pela professora após o programa de capacitação. A proximidade física estabelecida com o aluno, que começou a sentarse ao seu lado, parece ter também favorecido o aumento na frequência das interações.

0 gráfico 2 indica a frequência de turnos da díade nas rotinas da atividade pedagógica.

Gráfico 2 - Atividade pedagógica: frequência de turnos da professora e do aluno

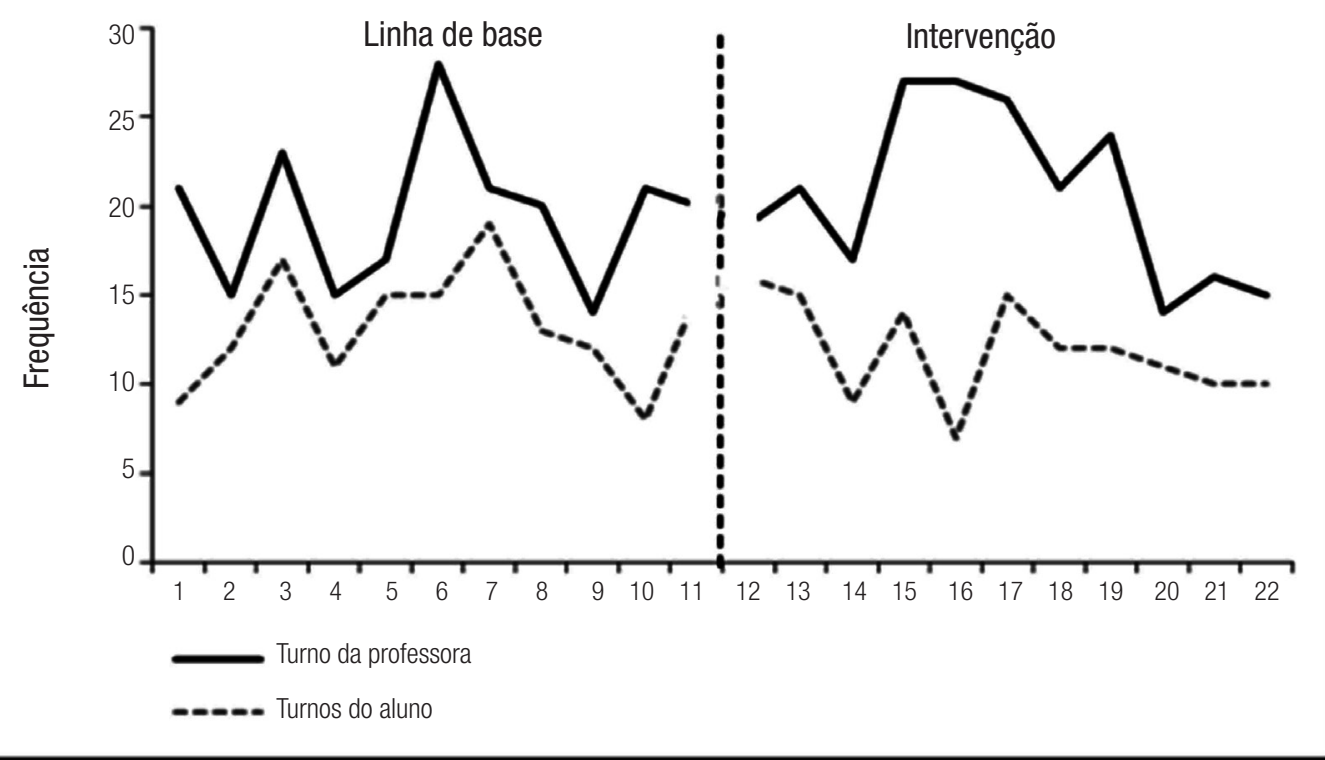

Fonte: dados da pesquisa

A maior frequência de interação da díade ocorreu durante as atividades pedagógicas. Esse padrão de respostas pode ser justificado pelo fato de ser o único momento em que a professora se sentava por mais tempo para interagir, individualmente, com o aluno. Apesar da elevada frequência, a qualidade da interação durante a fase de linha de base nem sempre era positiva.
Luan mostrava-se pouco responsivo às tarefas propostas pela professora antes da intervenção. Essa baixa responsividade se manifestava por comportamentos como: reduzida frequência em dirigir o olhar para a atividade, lassidão das mãos no momento de segurar os lápis, estereotipias motoras e tentativas de levantar-se da carteira. Nessas 
ocasiões, a professora ficava em pé, na frente dele, fazendo contenção física e empregando elogios para mantê-lo na tarefa.

0 comportamento de desinteresse de Luan pode ser atribuído à falta de compreensão ou motivação para realizar as atividades. De fato, dados observacionais revelaram que, muitas vezes, as tarefas propostas antes da intervenção pareciam inapropriadas para ele. Foram identificados poucos momentos em que Sônia individualizou a atividade pedagógica, considerando as necessidades educacionais específicas de Luan. Conforme aludem Oliveira e Machado (2007), a falta de adaptação curricular pode determinar a menor participação acadêmica do educando com necessidades educacionais especiais na sala de aula comum. Nesse contexto, as estereotipias motoras e outras condutas desadaptativas observadas durante essas atividades possivelmente refletem $o$ não envolvimento de Luan com as tarefas.

De maneira geral, após a implementação do programa de capacitação, as atividades propostas passaram a ser mais bem adaptadas e realizadas, em grande parte, com o apoio de pictogramas. Conforme sugerido na literatura, o uso de recursos visuais pode facilitar a compreensão de educandos com autismo
(WENDT, 2009). Esse parece ter sido o caso de Luan. Como possível consequência da introdução dos recursos de CAA, foi observada melhora qualitativa nas interações estabelecidas pela díade. Sônia passou a interagir com Luan não apenas para redirecioná-lo para a tarefa, mas também para tecer comentário e fazer solicitações durante as atividades.

0 aumento na frequência de turnos da professora foi acompanhado pelo aumento na frequência de turnos do aluno, tanto na rotina do lanche quanto durante as atividades pedagógicas. Na medida em que a professora diminuía a frequência de turnos, o aluno comportava-se de forma semelhante. Conforme argumenta Carvalho (1986, 2003, p. 90), "o comportamento do aluno influencia o comportamento do professor e vice-versa".

Para tratar a respeito dos efeitos do programa de capacitação nas modalidades de respostas empregadas pela díade, apresentamos a tabela 1. Ela indica o somatório da frequência dos turnos gestuais, verbais/vocais, pictográficos, verbais/vocais/gestuais e verbais/ vocais/pictográficos empregados pela díade durante todas as sessões de linha de base e intervenção na hora do lanche.

Tabela 1 - Somatório das frequências de modalidades de turnos empregados pela díade nas rotinas de lanche

\begin{tabular}{|c|c|c|c|c|}
\hline & \multicolumn{2}{|c|}{ Professora } & \multicolumn{2}{|c|}{ Aluno } \\
\hline & Linha de base & Intervenção & Linha de base & Intervenção \\
\hline Gestual & 10 & 13 & 23 & 57 \\
\hline Verbal/vocal & 25 & 69 & 16 & 32 \\
\hline Pictográfico & 6 & 2 & 12 & 29 \\
\hline Verbal/vocal/ Gestual & 20 & 33 & 1 & 5 \\
\hline Verbal/vocal/Pictográfico & 12 & 66 & 0 & 9 \\
\hline Total & 73 & 183 & 52 & 132 \\
\hline
\end{tabular}

Fonte: Dados da pesquisa.

De modo geral, esses dados refletem um aumento na frequência de turnos empregados pela díade, nas diferentes modalidades, na rotina de lanche, após o programa de capacitação. A única exceção é uma ligeira queda na frequência de turnos pictográficos pela professora.

Os gráficos 3 e 4 indicam a porcentagem de cada modalidade de turno empregada nas sessões de linha de base e intervenção na hora do lanche. 
Gráfico 3 - Porcentagem das modalidades de turnos empregados pela professora na hora do lanche

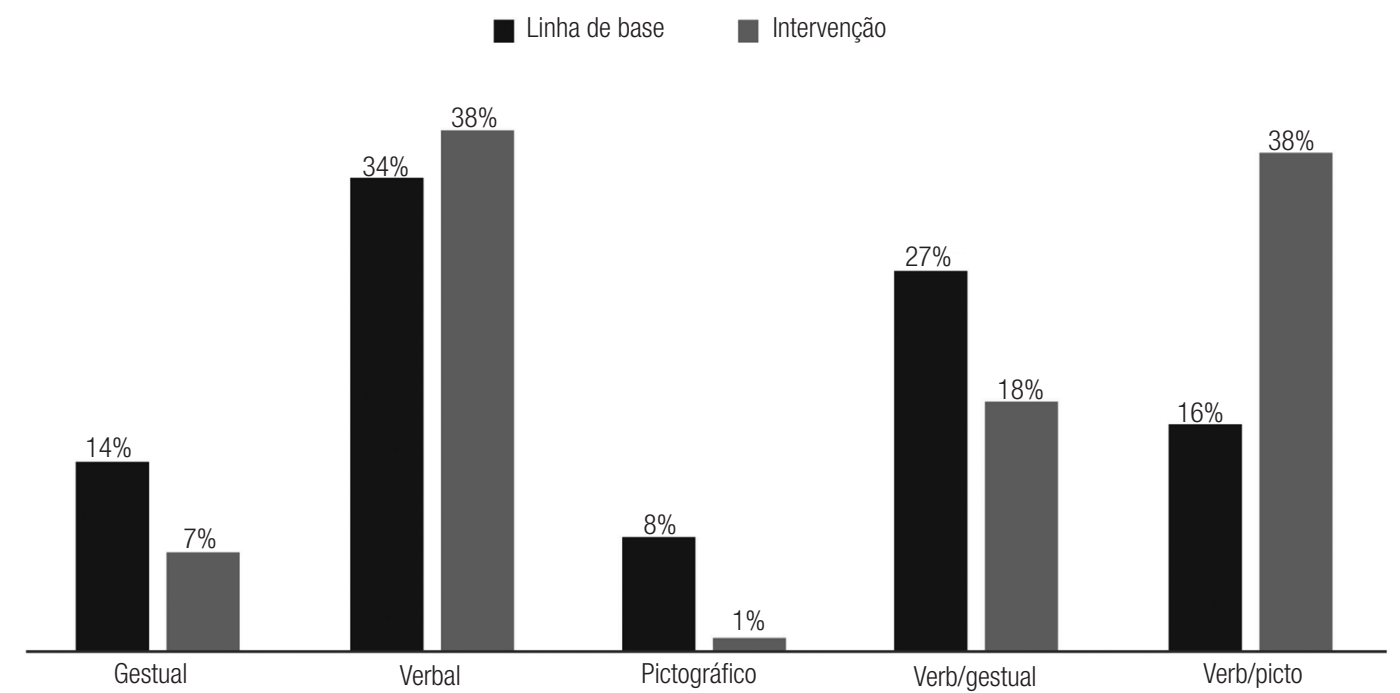

Fonte: Dados da pesquisa.

Gráfico 4 - Porcentagem das modalidades de turnos empregados pelo aluno na hora do lanche

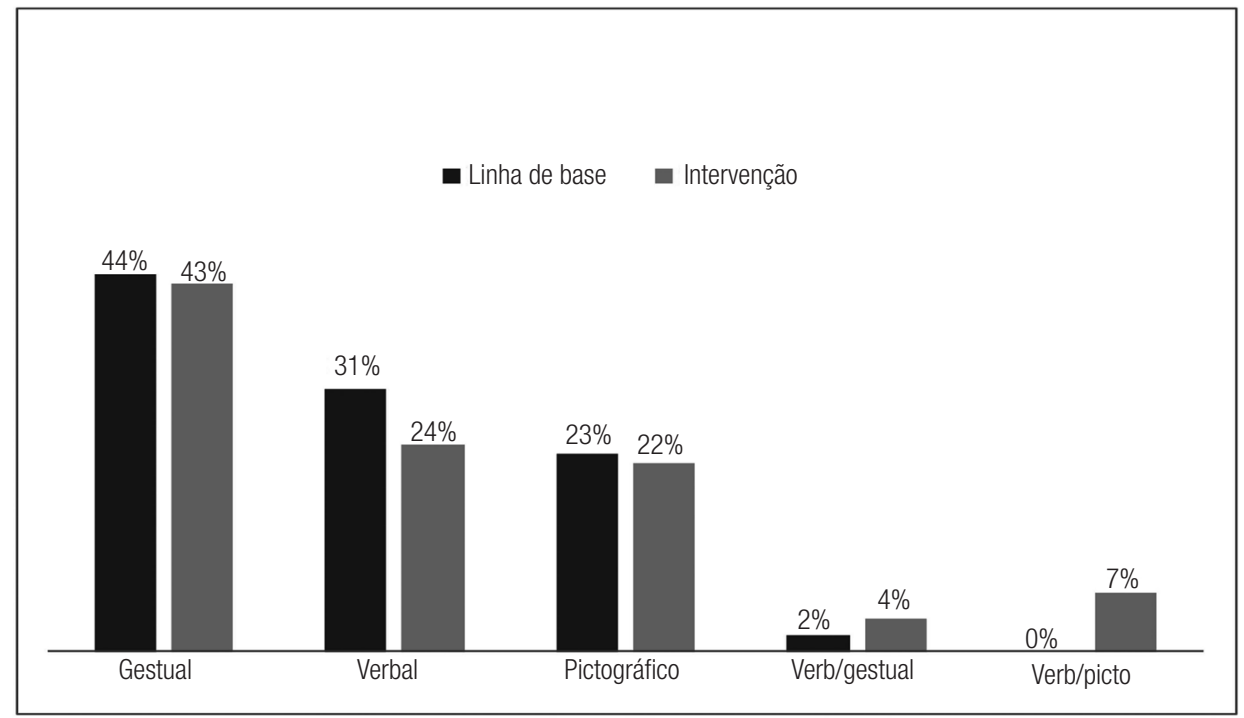

Fonte: Dados da pesquisa.

0 gráfico 3 revela que a professora, tipicamente, interagia com Luan por meio de verbalizações acompanhadas ou não por gestos, antes da intervenção. Após a capacitação, foi observado aumento expressivo no emprego dos pictogramas associados à verbalização/ vocalizações e diminuição de turnos gestuais.
Esses dados sugerem que Sônia substituiu os gestos pelo uso dos cartões de comunicação, como ilustra o trecho a seguir:

Luan está no canto da sala com um jogo de memória do "Menino Maluquinho" nas maõs. A professora pega o cartão de 
“lavar as mãos" que está sobre a sua mesa. Ela caminha até o menino e aponta para o cartão, enquanto diz: "Vamos lavar as mãos para depois lanchar, vamos Luan?" (GOMES, cd 2, 2010)

Em relação a Luan, é observada a preferência pelas modalidades gestuais e verbais/vocais, antes da intervenção, conforme revela o gráfico 4. Essa tendência é mantida após a capacitação. Vale ressaltar, no entanto, o aumento de turnos verbais/vocais associados ao uso de pictogramas. A partir desses dados é possível conjecturar que Luan passou a explorar outras modalidades de expressão, como o uso de pictogramas, após o programa de intervenção.

A Tabela 2, abaixo, indica o somatório da frequência dos turnos gestuais, verbais, pictográficos, verbais/gestuais e verbais/ pictográficos empregados pela díade durante todas as sessões de linha de base e intervenção na rotina de atividades pedagógicas.

Tabela 2 - Somatório das frequências de modalidades de turnos empregados pela díade nas rotinas de atividades pedagógicas

\begin{tabular}{|c|c|c|c|c|}
\hline & \multicolumn{2}{|c|}{ Professora } & \multicolumn{2}{|c|}{ Aluno } \\
\hline & Linha de base & Intervenção & Linha de base & Intervenção \\
\hline Gestual & 12 & 10 & 73 & 56 \\
\hline Verbal/vocal & 37 & 38 & 16 & 22 \\
\hline Pictográfico & 9 & 0 & 39 & 40 \\
\hline Verbal/vocal / Gestual & 65 & 69 & 16 & 12 \\
\hline Verbal/vocal /Pictográfico & 92 & 110 & 2 & 1 \\
\hline Total & 215 & 227 & 146 & 131 \\
\hline
\end{tabular}

Fonte: dados da pesquisa.

Assim como na rotina de lanche, a professora evidenciou aumento da frequência de turnos após a intervenção. Foi observada, também, uma diminuição no uso de pictogramas de forma isolada e um aumento na modalidade verbal, associada ou não ao uso dos cartões de comunicação por Sônia. Luan, por sua vez, diminuiu a frequência de turnos, após a implementação do programa. De forma específica, vocalizou mais e empregou menos gestos associados ou não a vocalizações. As outras modalidades de expressão não apresentaram alterações expressivas.

Os gráficos 5 e 6 , que se seguem, indicam a porcentagem de cada modalidade de turno empregada nas sessões de linha de base e intervenção nas atividades pedagógicas.

De forma geral, o programa de intervenção parece ter produzido poucas alterações no que concerne às modalidades de comunicação empregadas pela professora durante as rotinas pedagógicas. Sônia priorizou, antes e após a intervenção, o uso de verbalizações associadas a pictogramas e gestos. Em seguida, focalizou expressões verbais isoladas. Por fim, ela utilizou, de forma mais tímida, gestos e pictogramas para se comunicar com Luan antes e depois da intervenção. Vale ressaltar, no entanto, que, assim como na rotina de lanche, houve aumento no emprego das verbalizações associadas ao uso de pictogramas e diminuição na porcentagem geral de gestos.

Após o programa de intervenção, Luan apresentou leve crescimento no uso de formas pictográficas e verbais/vocais de expressão. Foram detectados a diminuição no emprego de gestos e gestos associados a verbalizações/vocalizações. A utilização de formas verbais de expressão associada ao uso da comunicação alternativa manteve-se estável nas duas fases do estudo. 
Gráfico 5 - Porcentagem das modalidades de turnos empregados pela professora na atividade pedagógica

Linha de base — Intervenção

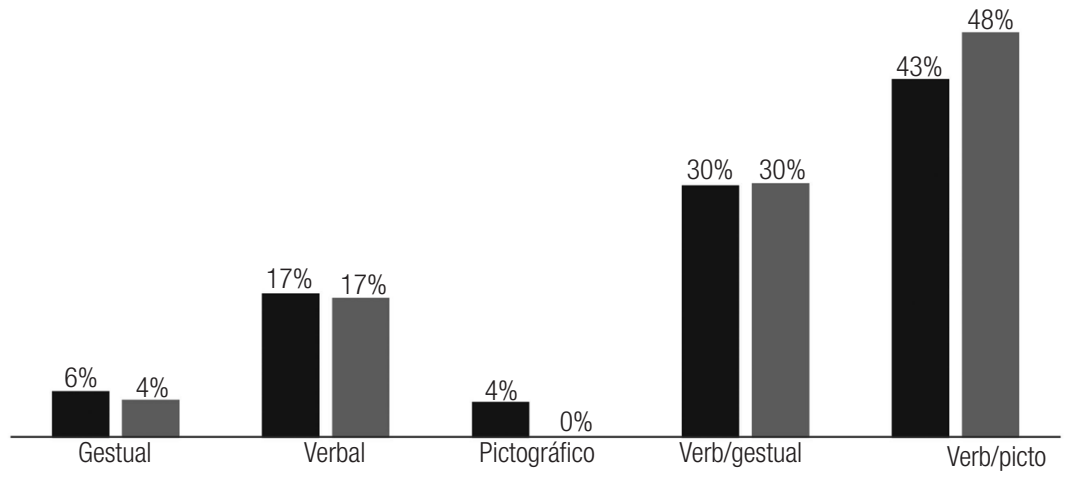

Fonte: dados da pesquisa.

Gráfico 6 - Porcentagem das modalidades de turnos empregados pelo aluno na atividade pedagógica

Linha de base Intervenção

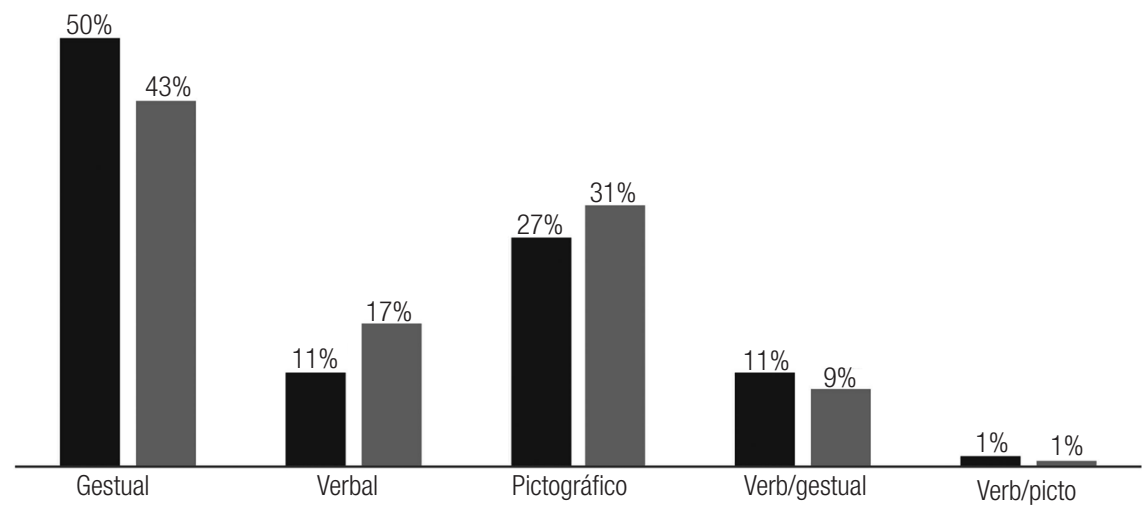

Fonte: dados da pesquisa.

\section{Discussão}

0 objetivo do presente estudo foi avaliar os efeitos de um programa de intervenção psicopedagógica nas interações comunicativas entre um aluno não falante, na faixa etária de 10 anos, com diagnóstico de autismo, e sua professora, no contexto da sala de aula comum. De forma específica, a investigação buscou identificar os efeitos do programa: a) no uso das ENE empregadas pela professora; b) nos turnos da díade; e c) nas modalidades de respostas da díade. 0 estudo foi delineado como uma pesquisa quase experimental do tipo A-B, tendo como cenário duas rotinas escolares: a hora do lanche e as atividades acadêmicas.

Os resultados indicaram momentos de baixa frequência de interação social entre 
Sônia e Luan no início da pesquisa. 0 uso de verbalizações como modalidade de expressão era predominante no repertório da professora, e o uso de gestos, no repertório de Luan. Como forma de aumentar a frequência de interações na díade, objeto do presente estudo, um programa de capacitação foi proposto à professora. Esta, ao rever sua prática nas sessões videografadas, expôs suas angústias e sinalizou as dificuldades de interagir com o aluno. Em seguida, em colaboração com a pesquisadora, identificou estratégias que poderiam favorecer essa interação. Nesse contexto, a pesquisadora apresentou as ENE e os recursos da CAA como forma de incitar a comunicação. 0 caráter individualizado do programa parece ter sido de fundamental importância para a adesão da professora à proposta de intervenção.

Após a capacitação, Sônia aumentou a frequência de turnos comunicativos e o uso de pictogramas associados a enunciados verbais, e demonstrou adequado emprego das ENE nas duas rotinas investigadas. A ampliação na frequência de turnos do aluno foi observada nas rotinas de lanche, mas não durante as atividades pedagógicas. 0 uso dos recursos de CAA por Luan ganhou notoriedade nas sessões de lanche, após o programa de capacitação. A utilização de gestos, no entanto, permaneceu sendo a principal forma de expressão de Luan, nas duas rotinas investigadas.

\section{Consideraçōes finais}

A literatura científica revela resultados promissores sobre o uso dos recursos da CAA e de Estratégias Naturalísticas de Ensino no desenvolvimento das habilidades de comunicação de indivíduos desprovidos de fala articulada, como os autistas. A transposição dessas práticas da teoria para a sala de aula pode ser viabilizada pela participação ativa do professor, como agente de intervenção, em programas instrucionais como o apresentado no presente manuscrito.

Limitações metodológicas são evidenciadas no presente estudo. Como em qualquer pacote de intervenções, em que múltiplas estratégias são ensinadas, é difícil estabelecer o nível apropriado de cada variável independente para otimizar respostas (TANNOCK; GIROLAMETTO, 1992). Ou seja, caso Sônia tivesse empregado as ENE ou os recursos da CAA com uma frequência distinta, haveria diferença na frequência de turnos e modalidades de expressões de Luan? Qual estratégia foi mais efetiva? Outros estudos podem enfocar a avaliação de cada estratégia, de forma isolada.

Foram observados perfis distintos de comunicação da professora nas duas rotinas investigadas, antes e após a intervenção. Enquanto Sônia priorizou a modalidade verbal nas rotinas do lanche, a utilização de verbalizações associadas ao uso dos pictogramas foi mais frequente durante as atividades pedagógicas, nas duas fases do estudo. Esse fenômeno pode evidenciar uma diferença estrutural nas rotinas investigadas. Em outras palavras, a atividade em si pode favorecer o uso de diferentes formas de expressão. Nesse sentido, é preciso que futuras pesquisas atentem para rotinas estruturalmente similares, quando delineamentos experimentais do tipo linha de base são empregados. 


\section{Referências}

ALVES, Márcia Doralina. As representações sociais de professores acerca da inclusão de alunos com distúrbios globais do desenvolvimento. 2005. 103 f. Dissertação (Mestrado em Educação) - Universidade Federal de Santa Maria, Santa Maria, 2005.

AMERICAN PSYCHIATRIC ASSOCIATION-APA. Manual diagnostic e estatístico de transtornos mentais - DSM-IV-TR. Porto Alegre: Artemed, 2002.

ARAÚJO, Maria Isabel; NUNES, Leila Regina de Paula. Facilitando e ampliando a comunicação e os resíduos da fala através de sistema computadorizado de comunicação alternativa. In: NUNES, Leila Regina (Org.). Favorecendo o desenvolvimento da comunicação em crianças e jovens com necessidades educacionais especiais. Rio de Janeiro: Dunya, 2003. p. 111-123.

CARVALHO, Ana Maria. Pimenta. Estudo descritivo da interação professor-aluno: uma abordagem individualizada. 1986. Dissertação (Mestrado em Educação Especial) - Universidade Federal de São Carlos, São Carlos, 1986.

CUNHA, Ana Cristina Barros da. Promovendo aquisição de linguagem funcional em criança deficiente visual: 0 efeito de um treinamento de mãe em procedimentos de ensino naturalístico. Temas Psicol. [online], v. 5, n. 2, p. 33-56, 1997.

DANELON, Maria Cristina T. de Moraes. As interações sociais de alunos com dificuldades de comunicação oral a partir da inserção de recurso da comunicação alternativa e ampliada associada aos procedimentos do ensino naturalístico. 2009. Tese (Doutorado em Educação) - Centro de Educação e Humanidades, Faculdade de Educação, Rio de Janeiro, 2009.

DELIBERATO, Débora. Habilidades expressivas de um aluno não falante com diferentes interlocutores. In: NUNES, Leila Regina D'Oliveira de Paula Pelosi; BONADIU, Myriam; GOMES, Márcia Regina. Um retrato da comunicação alternativa no Brasil: relatos de pesquisa e experiências. Rio de Janeiro: Quatro Pontos, FINEP, 2009. p. 137-142.

ELSABBAGH, Mayada et al. Global prevalence of autism and other pervasive developmental disorders. Autism Research, Hoboken, n. 5, p. 160-179, 11 abr. 2012.

FAGUNDES, Antônio. Descrição, definição e registro de comportamentos. São Paulo: Edicon, 1985.

GLENNEN, Sharon. Handbook of augmentative and alternative communication. London: Singular Publishing Group, 1992.

GOMES, Rosana Carvalho. Interações comunicativas entre uma professora e um aluno com transtorno invasivo do desenvolvimento na escola regular. 2011. 155 f. Dissertação (Mestrado em Educação) - Universidade Federal do Rio Grande do Norte, Natal, 2011.

HALL, Laura J. Autism Spectrum Disorders: from theory to practice. Upper Saddle River, NJ: Merrill Prentice Hall, 2012.

HEFLIN, Juane; ALAIMO, Donna Florino. Students with autism spectrum disorders: effective instructional practices. Upper Saddle River, N.J.: Pearson Prentice Hall, 2007.

KENNEDY, Craig H. Single-case designs for educational research. Boston: Pearson Education, Inc, 2005.

KLIN, Ami. Autismo e Síndrome de Asperger: uma visão geral. Revista Brasileira de Psiquiatria, v. 28, supl. 1, p. 3-11, 2006.

KUEHN, Bridget M. Autism spectrum disorders common. Journal of the American Medical Association, v. 297, p. 940, 2007.

LAMONICA, Dionísia A. C. Utilização de variações do ensino incidental para promover 0 aumento das habilidades linguísticas de uma criança diagnosticada autista. Temas em Psicologia, São Paulo, v. 1, n. 2, p. 127-130, 1993.

MACEDO, Elizeu Coutinho de; ORSATI, Fernanda. Comunicação alternativa. In: SCHWARTZMAN, José Salomão; ARAÚJO, Ceres Alves de. Transtornos do espectro do autismo. São Paulo: Memnon, 2011. p. 244-254.

MARTINS, Maria Rubia Rodrigues. Inclusão de alunos autistas no ensino regular: concepções e práticas pedagógicas de professores regentes. 2007. 159 f. Dissertação (Mestrado em Psicologia) - Universidade Católica de Brasília, 2007. 
MCGREGOR, Evelyn; CAMPBELL, Elaine. The attitudes of teachers in Scotland to the integration of children with autism into mainstream schools. Autism, v. 5 (2), p. 89-207, 2001.

NATIONAL AUTISM CENTER (Ed.). Evidence-based practice autism in the schools: a guide to providing appropriate interventions to students with autism spectrum disorders. 2. ed. Randolph, Massachusetts: National Autism Center, 2011. Disponível em: <http:// www.nationalautismcenter.org/pdf/NAC\%20Ed\%20Manual_FINAL.pdf>. Acesso em: 19 fev. 2013.

NUNES, Débora Regina de Paula. Efeitos dos procedimentos naturalísticos no processo de aquisição de linguagem através de sistema pictográfico de comunicação em criança autista. Dissertação (Mestrado em Educação) - Faculdade de Educação, Universidade do Estado do Rio de Janeiro, 2000.

. Autismo e inclusão: entre realidade e mito. In: MENDES, Enicéia Gonçalves; ALMEIDA, Maria Amélia (Orgs.). Dimensões pedagógicas nas práticas de inclusão escolar. 1. ed. Marília: Abpee, 2012, v. 2, p. 279-292.

Enhancing the use of augmentative communication systems of children with autism through caregiverimplemented naturalistic teaching strategies. Tese (Doctoral dissertation Florida State University) - Dissertation Abstracts International, 2005. Disponivel em: <http://etd. lib.fsu.edu/theses/available/etd-12062005-185208/>. Acesso em: 12 fev. 2010.

. AAC interventions for autism: a research summary. International Journal of Special Education. v. 23, p. 17-26, 2008.

FREIRE, Janielle; AZEVEDO, Mariana Orrico. Ampliando a comunicação de aluno com autismo: o professor enquanto agente de intervenção. In: DELIBERATO, Débora; GONÇALVES, Maria de Jesus; MACEDO, Elizeu Coutinho de. Comunicação alternativa: teoria, prática, tecnologias e pesquisa. São Paulo: Memmon Científicas, 2009. p. 115-131.

NUNES, Leila Regina de Paula. Métodos naturalísticos para o ensino da linguagem funcional em indivíduos com necessidades especiais. In: ALENCAR, Eunice Soriano de (Org.). Novas contribuições da psicologia aos processos de ensino e aprendizagem. São Paulo: Cortez, 1992.

OLIVEIRA, Anna Augusto Sampaio de. Representações sociais sobre educação especial e deficiência: 0 ponto de vista de alunos e professores. Tese (Doutorado em Educação) - Universidade Estadual Paulista, Marília/SP, 2002.

OLIVEIRA, Eloiza de; MACHADO, Katia da Silva. Adaptações curriculares: caminho para uma educação inclusiva. In: GLAT, Rosana. Educação inclusiva: cultura e cotidiano escolar. Rio de Janeiro: Sete Letras, 2007. p. 36-52.

PAULA Cristiane; RIBEIRO, Sabrina; FOMBONNE, Eric; MERCADANTE, Marcos. Brief report: prevalence of pervasive developmental disorder in Brazil. A pilot study. Journal of Autism and Developmental Disorders, 2011. p. 1200-1206.

PAULA, Kelly Maria Pereira de; NUNES, Leila Regina de Paula. A comunicação alternativa no contexto do ensino naturalístico. In: NUNES, Leila Regina de Paula. (Org.). Favorecendo o desenvolvimento da comunicação em crianças e jovens com necessidades educacionais especiais. Rio de Janeiro: Dunya, 2003. p. 95-109.

PAULA, Kely Maria Pereira de; ENUMO, Sônia Regina Fiorim. Avaliação assistida e comunicação alternativa: procedimentos para a educação inclusiva, Revista Brasileira de Educação Especial, Marília, v. 13, n. 1, Apr. 2007.

PEREIRA, Alessandra; RIESGO, Rudimar S.; WAGNER, Mario B. Autismo infantil: tradução e validação da Childhood Autism Rating Scale para uso no Brasil. J. Pediatr. Rio J. [online]. 2008, v. 84, n. 6, p. 487-494.

ROBERTSON, Kristen; CHAMBERLAIN, Brandt; KASARI, Connie. General education teachers' relationships with included students with autism. Journal of Autism and Developmental Disorders, 33, p. 123-130, 2003.

SERRA, Dayse Carla Genero. Entre a esperança e o limite: um estudo sobre a inclusão de alunos com autismo em classes regulares. Rio de Janeiro, 2008. 124p. Tese (Doutorado) - Departamento de Psicologia, Pontifícia Universidade Católica do Rio de Janeiro, Rio de Janeiro, 2008.

SHIRMER, Carolina R.; NUNES, Leila Regina de Paula. Perfil de alunos de pedagogia que estão freqüentando curso de formação inicial de professores para atuação na área de tecnologia assistiva com ênfase em comunicação alternativa e ampliada. SEMINÁRIO NACIONAL DE PESQUISA EM EDUCAÇÃO ESPECIAL, 5, São Paulo, Anais... São Paulo: AVPEE, 2009. 
SIMPSON, Richard. Evidence-based practices and students with autism spectrum disorders. Focus on Autism and Other Developmental Disabilities, v. 20, n. 3, p. 140-149, 2005.

SOUZA, Vera; Recursos alternativos para o desenvolvimento da comunicação. In: NUNES, Leila Regina. (Org.). Favorecendo o desenvolvimento da comunicação em crianças e jovens com necessidades educacionais especiais. Rio de Janeiro: Dunya. 2003. p. 219-233.

TANNOCK, Rosemary; GIROLAMETTO, Luigi. Reassessing parent-focused language intervention programs. In: WARREN, Steven F.; REICHLE, Joe (Eds). Causes and effects in communication and language intervention: communication and language intervention series. v. 1. Baltimore, MD: Paul H. Brookes Publishing, 1992. p. 49-79.

WALTER, Cátia; ALMEIDA, Maria Amélia. Avaliação de um programa de comunicação alternativa e ampliada para mães de adolescentes com autismo. Revista Brasileira de Educação Especial, Marília, v. 16, n. 3, dez. 2010.

WENDT, Oliver. Research on the use of graphic symbols and manual signs. In: MIRENDA, Pat; IACONO, Teresa (Eds.). Autism spectrum disorders and AAC. Baltimore: Paul H. Brookes, 2009. p. 83-137.

Recebido em: 25.09.2012

Aprovado em: 24.04.2013

Rosana Carvalho Gomes é professora da rede Estadual de Educação do Estado do Piauí e pedagoga na rede Municipal de Educação de Teresina-PI, pedagoga e mestre em Educação pela Universidade Federal do Rio Grande do Norte.

Débora R. P. Nunes é docente dos Programas de Graduação e Pós-Graduação em Educação da Universidade Federal do Rio Grande do Norte; doutora em Educação Especial pela Florida State University; Mestre em Educação pela Universidade do Estado do Rio de Janeiro; psicóloga pela Universidade Federal do Rio de Janeiro. 